\title{
Computational Approaches and Data Analytics in Financial Services: A Literature Review
}

\author{
Dimitris Andriosopoulos ${ }^{\mathrm{a}}$, Michalis Doumpos ${ }^{\mathrm{b}}$, Panos M. Pardalos ${ }^{\mathrm{c}}$, Constantin \\ Zopounidis ${ }^{\mathrm{b}, \mathrm{d}}$

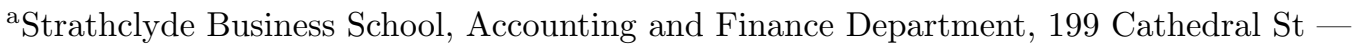 \\ Glasgow, G4 0QU, UK; ${ }^{b}$ Technical University of Crete, School of Production Engineering and \\ Management, University Campus, 73100 Chania, Greece; ${ }^{c}$ University of Florida, Department \\ of Industrial and Systems Engineering, Center for Applied Optimization, Gainesville, USA; \\ dAudencia Business School, Institute of Finance, 8 route de la Jonelire, 44312 Nantes, France
}

\author{
ARTICLE HISTORY \\ Compiled November 8, 2018
}

\begin{abstract}
The level of modeling sophistication in financial services has increased considerably over the years. Nowadays, the complexity of financial problems and the vast amount of data require an engineering approach based on analytical modeling tools for planning, decision making, reporting, and supervisory control. This paper provides an overview of the main financial applications of computational and data analytics approaches, focusing on the coverage of the recent developments and trends. The overview covers different methodological tools and their uses in areas, such as portfolio management, credit analysis, banking, and insurance.
\end{abstract}

\section{KEYWORDS}

Financial services; data analytics; risk management; financial modeling

\section{Introduction}

The sector of financial services has undergone major changes over the past decades. On the one hand, the range of operations in the financial sector has grown significantly, covering a wide range of new banking, investment, and insurance products, together with new financing tools and corporate finance practices. On the other hand, the sector has been increasingly relying on new technologies, not only as tools for providing improved services to individual and corporate clients, but also for improving practices in regard to decision making, risk analysis, monitoring, and reporting. Finally, a number of changes in the regulatory framework have imposed new requirements for the way financial services are designed, provided, and monitored.

Addressing the challenges that arise due to such developments, often requires a high level of sophistication for the analytical tools and techniques used in financial services. Traditionally, the field of finance has relied on normative and descriptive approaches, usually based on statistical and econometric techniques, for building theories regarding the understanding of the financial world. Nevertheless, going beyond financial theory, 
prescriptive and predictive systems are also crucial for decision making in financial services, providing operational guidance to decision makers (investors, managers, policy makers) on specific instances of financial decision problems. Combined with financial theory and models, such systems support financial decision making through comprehensive approaches that integrate theory, data, and expert judgment.

However, the context described above for the sector of financial services, poses various challenges on the development of realistic and effective analytic models and techniques in this field. First, the existence of deep uncertainties requires the development and extensive testing of robust models. Second, big data are becoming increasingly important in financial services, but financial data are usually unstructured and noisy. The volume of the available data also raises computational issues, particularly in cases where real-time decision support is required. Finally, model transparency has also become an important issue for reporting and supervisory control of the practices followed in the financial sector.

The scope of financial decision support approaches and their range of applications has been extended considerably since Markowitz's work on portfolio selection (Markowitz, 1959) and the first applications of linear/goal programming and decision theory to problems related to financial planning and investment appraisal (Charnes, Cooper, \& Ijiri, 1963; Hillier, 1963; Myers \& Pogue, 1974). Nowadays, a wide arsenal of optimization models, decision making approaches, data analytic techniques, and computational solution algorithms, are available and applicable to various traditional and new financial products/services.

The objective of this paper is to provide an overview of the current status and recent developments in this area, focusing on computational and data analytic approaches. Given that presenting a comprehensive bibliographic review of the relevant literature is quite difficult, due to the wide range of the field and the analytical methodologies involved, we cover in more detail two popular areas in financial services, namely portfolio management and credit risk analysis. The review focuses on analytical approaches such as exact optimization techniques, metaheuristics, machine learning approaches, and decision analysis.

The rest of the paper is organized as follows. In section 2 we describe the context of financial decisions and the relevance/contributions of various types of analytical approaches. Section 3 reviews the recent literature on the applications of such approaches in portfolio management, credit risk analysis, as well as in other fields areas of financial services. Finally, section 4 concludes the paper and discusses some future research issues.

\section{Financial decision making}

Decision problems in financial services cover a wide range of areas related to financing decisions and investment planning, as well as supervisory control. Recently, most of the focus in research and practice has been on risk management issues for financial institutions (banks, insurance companies, funds, etc.). Moreover, issues related to the design and management of financial services provided to consumers and corporate clients has also attracted much interest, particularly with the emergence of new electronic platforms and distribution channels (e.g., online transactions, crowdfunding, cryptocurrencies), which have led to the recent rise of financial technology (fintech).

The widespread use of analytical models for financial decision making has been driven by various factors. One of the most important ones has been the regulatory 
requirements imposed during the past two decades. For instance, starting with the first Basel Committee capital accord in 1988, and its revisions in Basel II/III, banks are required to follow a strict set of guidelines and rules for measuring, managing, and reporting their risk exposures (credit, liquidity, operational, and market risks). Similar regulatory requirements have also been introduced in other sectors of financial services (e.g., the European Solvency II directive for insurance regulation, the IFRS 9 for financial reporting, etc.). Meeting the requirements imposed by the regulatory environment, requires the use of analytical approaches, which set a systematic basis for planning, decision making, and control.

Beyond the tightening regulatory provisions, the use of analytical models has been also promoted to meet the increasing complexity of designing and providing advanced financial services to consumers and corporate clients. The massive data that are nowadays available create many opportunities. For instance, for selecting financial assets for investment purposes, except for standard financial and market data (e.g., fundamentals and technical indicators), asset managers now also rely on sentiment analysis and news analytics (Schumaker, Zhang, Huang, \& Chen, 2012; Smales, 2016), as well as information about corporate governance and social responsibility (e.g., social responsible investments; Ballestero, Bravo, Pérez-Gladish, Arenas-Parra, \& Plà-Santamaria, 2012; Hallerbach, Ning, Soppe, \& Spronk, 2004). The existence of vast data create opportunities for improving financial decisions, but this is a challenging task because the data should be transformed to useful information.

Models for financial decision making are used both at the strategic and the tactical/operational level. The former involves long-term decisions for financial organizations regarding their financial planning and the management of their assets. Examples of strategic financial decisions include decisions about mergers and acquisitions, initial public offerings, long-term capital budgeting and financial planning, loan portfolio management, as well as decisions related to corporate capital structure and systemic risk analysis. On the other hand, models at the operational level focus on daily operations providing guidance and decision support on elementary instances according to the targets and goals set at the strategic level.

In this context, financial models combine normative, descriptive, and prescriptive elements, either in a static or a dynamic setting. While various analytical and computational approaches are used for financial modeling and decision making, in this review we distinguish between the following broad categories:

- Optimization models: Optimization models of various forms (e.g., linear and non-linear, dynamic, stochastic, fuzzy, multiobjective, etc.) are widely used for asset allocation, financial planning, and risk management (Zenios, Consiglio, \& Nielsen, 2010). As it will be explain later in section 3.1.1, financial optimization models originate from the fundamental work of Markowitz (1959) on portfolio selection. Since then financial optimization has advanced to cover various other areas in investments, banking, insurance, and corporate finance. However, as models become more sophisticated, standard solution algorithms are not always feasible, from a computational point of view. This has led to the wide use of metaheuristics, which are well-suited for for complex problems with non-linear and combinatorial structure (Maringer, 2005). In financial services, such problems commonly arise when modeling realistic features (e.g., cardinality constrained portfolio optimization) or when dealing with complex risk measures.

- Data analytics and machine learning: As explained above, financial services have become a data-intensive sector. Artificial intelligence (AI) approaches based on 
machine learning are particularly well-suited as data analytics tools, enabling the development of descriptive, prescriptive, and predictive models for financial decision making. Such models allow the identification of non-trivial patterns in massive and ill-structured financial data. Supervised and unsupervised learning techniques for classification and regression are the ones most commonly used, together with intelligent optimization systems (e.g., reinforcement learning, Bloembergen, Tuyls, Hennes, \& Kaisers, 2015).

- Decision analysis and decision support systems: In contrast to AI approaches, which usually adopt automated procedures for decision making, decision analysis techniques rely on the domain knowledge and expertise of financial decision makers (Zopounidis, Doumpos, \& Niklis, 2018). Incorporating this type of information to financial models enhances their comprehensibility and adds realism, which may not be fully covered by pure data-driven approaches. Combined with other analytical approaches (optimization-based or AI), this may reduce model risk, which has become a crucial issue in financial modeling (Christodoulakis \& Satchell, 2008). Moreover, the constructive approach often adopted by decision analysis approaches promotes the learning process, thus providing insights into various aspects of financial decision problems and the preferences of the actors involved (e.g., managers, investors, policy-makers, etc.). Decision analysis tools are often implemented in decision support systems, which integrate data management, analytics, visualization, and reporting tools.

The existing arsenal of analytical techniques practically covers all areas of financial modeling and decision making. However, in many cases a single approach may not be enough as the multi-faced nature of problems in financial services may not be fully covered by one methodology. Thus, hybrid systems are common, combining elements and ideas from various disciplines.

\section{Overview of applications in financial services}

Having defined the framework for financial decisions and the main analytical tools used in this area, in this section an overview of the recent literature is presented regarding the applications of various types of analytical approaches in different areas of financial services. The overview starts with portfolio management, followed by credit risk analysis, as well as other applications in banking and insurance.

\subsection{Portfolio management}

The area of portfolio management is one of the most widely studied domains in financial decision making. In financial services, portfolio management is involved with the design and management of financial investments, usually consisting of assets from the equity markets, as well as funds, fixed income investments, currencies, and commodities. Nevertheless, the many principles and techniques used in portfolio management also applied in portfolios of real investment (e.g., project portfolios) as well as in banking (e.g., loan portfolios), and insurance.

The portfolio management process involves various issues (Doumpos \& Zopounidis, 2014; Xidonas, Mavrotas, Krintas, Psarras, \& Zopounidis, 2012). In the following subsections, we cover asset screening, portfolio allocation, and trading, focusing on the computational and data analytics methodologies used in each area. 


\subsubsection{Asset screening}

Asset screening is the first step of the portfolio management process, which focuses on the selection of the most suitable investment assets. Given the vast number of assets now available to investors in the global markets, the screening and selection process is crucial for a successful investment strategy. The screening process takes into account various factors about the investment environment, the trends in the markets, as well as fundamental and technical factors about specific assets. For instance, for stock selection portfolio managers typically consider financial data about the future prospects of the firms, valuation indicators, as well as technical indicators that capture short to medium-term trends in equity prices. While asset selection by professionals is often based on univariate decision rules, empirical evidence has shown that the combined use of different selection attributes may provide significantly improved results (Pätäri, Karell, Luukka, \& Yeomans, 2018; van der Hart, Slagter, \& van Dijk, 2003).

The methodologies and analytical tools for asset screening can be categorized in two main categories. The first category is based on judgmental approaches, which rely on descriptive and prescriptive approaches, often based on inputs provided by investors and portfolio managers about their investment policies and preferences. The second category focuses on automated procedures, based on models for predicting future returns. Often such models are used in the context of asset trading, rather than for selecting investments for portfolio construction. The literature on trading models is covered in sub-section 3.1.3.

Table 1 lists some recent studies on the use of various methodologies for asset selection, focusing on the selection of stocks and funds. It is interesting that approaches based on data envelopment analysis and multicriteria decision making are quite popular in this area. Such techniques are based on data-driven and expert judgment approaches to evaluate the performance of a set of assets on the basis of their fundamentals. On the other hand, data analytics models such as neural networks, neuro-fuzzy models, support vector machines, and evolutionary methods, have been mainly used in a predictive modeling context to estimate the growth prospects of assets and identify those that are more likely to be profitable investments.

Table 1. Studies on the use of analytical methodologies for asset selection

\begin{tabular}{lll}
\hline Study & Methodology & Asset \\
\hline Edirisinghe and Zhang (2007) & DEA & Stocks \\
H.-H. Chen (2008) & DEA & Stocks \\
Edirisinghe and Zhang (2008) & DEA & Stocks \\
Quah (2008) & ANN, ANFIS & Stocks \\
Sevastjanov and Dymova (2009) & MCDA, Fuzzy & Stocks \\
Hamzaçebi and Pekkaya (2011) & GRA & Stocks \\
C.-F. Huang (2012) & GA, SVM & Stocks \\
Xidonas, Mavrotas, and Psarras (2010) & MCDA & Stocks \\
Yan and Clack (2010) & GP & Funds \\
Xidonas, Mavrotas, Zopounidis, and Psarras (2011) & MCDA & Stocks \\
Babalos, Philippas, Doumpos, and Zopounidis (2012) & MCDA & Funds \\
Kiris and Ustun (2012) & Fuzzy MCDM & Stocks \\
H. Liu, Mulvey, and Zhao (2016) & Copula models & Stocks \\
Song, Liu, and Yang (2017) & ML, SA & Stocks \\
Allevi, Basso, Bonenti, Oggioni, and Riccardi (2018) & DEA & Funds \\
Galagedera, Roshdi, Fukuyama, and Zhu (2018) & DEA & Funds \\
do Castelo Gouveia, Neves, Dias, and Antunes (2018) & DEA & Funds \\
Pätäri et al. (2018) & MCDA & Stocks \\
\hline
\end{tabular}

ANFIS: adaptive neuro-fuzzy inference system, ANN: artificial neural network, DEA data envelopment analysis, GA: genetic algorithm, GP: genetic programming, MCDA: multicriteria decision analysis, SA: sentiment analysis, SVM: support vector machines 


\subsubsection{Capital allocation}

In financial services, asset allocation is a broad field involved with the design of financial investments combining multiple assets into portfolios that meet the investor's riskreturn preferences. Usually, different asset classes can be considered, such as equities, fixed income securities, funds, derivatives, currencies, and commodities. The foundations of quantitative asset allocation have been set by the mean-variance (MV) portfolio selection model of Markowitz (1959), which is expressed as a standard quadratic programming $(\mathrm{QP})$ problem:

$$
\begin{array}{ll}
\min & \mathbf{x}^{\top} \mathbf{\Sigma} \mathbf{x} \\
\text { subject to }: & \mathbf{r}^{\top} \mathbf{x} \geq R \\
& \mathbf{1}^{\top} \mathbf{x}=1 \\
& \mathbf{z} \leq \mathbf{x} \leq \mathbf{u}
\end{array}
$$

where $\mathbf{x}=\left(x_{1}, \ldots, x_{n}\right)$ denotes the vector of asset allocations (proportion of capital invested in a set of $n$ assets), $\mathbf{z}=\left(z_{1} \ldots, z_{n}\right)$ and $\mathbf{u}=\left(u_{1}, \ldots, u_{n}\right)$ are vectors of lower and upper bounds for the allocations, $\boldsymbol{\Sigma}=\left(\sigma_{i j}\right)_{i, j=1}^{n}$ is the covariance matrix of asset returns, $\mathbf{r}=\left(r_{1}, \ldots, r_{n}\right)$ is the vector of expected (mean) asset returns, $R$ is a user-defined level of required return, and $\mathbf{1}$ denotes a vector of ones.

The MV model set the grounds for numerous extensions to cover more realistic and complex cases. Some typical examples include:

- Different risk measures providing a finer characterization of investment risk, beyond the MV perspective that relies solely on the variance of returns. Over the years, different risk measures have been introduced focusing on a more detailed description of the returns distribution with higher-order moments (skewness and kurtosis; Jondeau \& Rockinger, 2006; Ryoo, 2007), tail-risk measures (value-atrisk, conditional value-at-risk; Jorion, 2009; Rockafellar \& Uryasev, 2002), and other risk-return performance measures (e.g., omega ratio; Kapsos, Christofides, \& Rustem, 2014).

- Cardinality constrained asset allocation, involving portfolios consisting of a fixed maximum number of assets selected automatically through an optimization model from a given pool of options (Bertsimas \& Shioda, 2007; Chang, Meade, Beasley, \& Sharaiha, 2000; Woodside-Oriakhi, Lucas, \& Beasley, 2011).

- Transaction costs and other real features that describe actual investment strategies in more a realistic manner. Some indicative issues involve transaction costs, round-lot constraints, portfolio diversification goals, and other considerations such as social responsible investments (Angelelli, Mansini, \& Speranza, 2008; Hallerbach et al., 2004).

- Index tracking portfolio optimization, involving passive investment strategies that replicate the returns of a chosen market index (Andriosopoulos, Doumpos, Papapostolou, \& Pouliasis, 2013; Andriosopoulos \& Nomikos, 2014; de Paulo, de Oliveira, \& do Valle Costa, 2016; Filippi, Guastaroba, \& Speranza, 2016; Mezali \& Beasley, 2013; Strub \& Baumann, 2018; Zhao, Xu, Wang, \& yi Zhang, 2018)

- Dynamic portfolio selection that extends the traditional MV static framework to multiple time periods, either in a discrete or a continuous setting (Brown \& Smith, 2011; Q. Liu, Guo, \& Wang, 2012).

The incorporation of such aspects into asset allocation models has led to various advances on at least two major directions: 
- Algorithmic approaches: Several of the above extensions and variants require the solution of complex optimization problems. For instance, in cardinality constrained asset allocation and index tracking, problem (1) is reformulated in a mixed-integer QP form with binary variables indicating whether an asset is included in the portfolio or not. This variant is difficult to solve to optimality with exact algorithms due to its combinatorial nature. The optimization of alternative performance measures, such as value-at-risk (Babat, Vera, \& Zuluaga, 2018; Gaivoronski \& Pflug, 2005) and models based on higher-order moments (C. Chen \& sha Zhou, 2018; Maringer \& Parpas, 2007), also poses computational challenges. The same also applies to models that incorporate transaction costs and other real features (Glen, 2011; Jobst, Horniman, Lucas, \& Mitra, 2001; Lobo, Fazel, \& Boyd, 2006). In such cases, algorithms (heuristics and metaheuristics) that lead to approximate optimal solutions in reasonable time, have been become very popular and have been used a variety of different settings (Ertenlice \& Kalayci, 2018; Maringer, 2005).

- Modeling formulations: Except for algorithmic advances, the consideration of different portfolio performance measures and other realistic features, has led to various modeling developments, such as

o portfolio selection with multiple objectives and goals (Aouni, Doumpos, Pérez-Gladish, \& Steuer, 2018; Colapinto, La Torre, \& Aouni, 2018; Giesecke, Kim, Kim, \& Tsoukalas, 2014; Xidonas, Mavrotas, Hassapis, \& Zopounidis, 2017; Xidonas et al., 2012),

o stochastic approaches (Brown \& Smith, 2011; Dupačová \& Kopa, 2012; Filomena \& Lejeune, 2012; Hibiki, 2006; Östermark, 2017; Post \& Kopa, 2017),

- multiperiod and continuous time models (Bjrk, Murgoci, \& Zhou, 2012; Bo \& Capponi, 2014; Calafiore, 2008; Çelikyurt \& Özekici, 2007; Jung \& Kim, 2015; Pfister, Utz, \& Wimmer, 2014),

- fuzzy models (Gupta, Mehlawat, \& Saxena, 2008; Vercher \& Bermudez, 2013; X. Xu, He, Chen, \& Zhang, 2015),

- robust optimization (Ban, Karoui, \& Lim, 2018; Bertsimas \& Sim, 2004; Fabozzi, Kolm, Pachamanova, \& Focardi, 2007; Goldfarb \& Iyengar, 2003; W. C. Kim, Kim, Ahn, \& Fabozzi, 2012; Lotfi \& Zenios, 2018), and

- network models (Boginski, Butenko, \& Pardalos, 2005; X. Guo, Zhang, \& Tian, 2018; Kalyagin, Koldanov, Koldanov, \& Pardalos, 2017).

\subsubsection{Trading}

The trading process in portfolio management is involved with dynamically rebalancing a portfolio of assets or a single asset to maximize the investors terminal wealth (also taking into account risk considerations). Trading systems combine various fundamental and technical factors to identify market trends and profitable trades. Except for standard financial time series data, other information has become very popular recently, including news analytics and sentiment analysis (Bordino et al., 2012; Geva \& Zahavi, 2014; Mitra \& Mitra, 2011; Schumaker et al., 2012; Treleaven, Galas, \& Lalchand, 2013). Moreover, with the advances in electronic trading systems, algorithmic trading (including high-frequency trading; Goldstein, Kumar, \& Graves, 2014) has dominated the field, with various reports from the USA and Europe indicating that automated systems account for more than $40-50 \%$ of the total trading volume in the 
equities markets. ${ }^{1}$

The research on the development of trading systems has focused on various machine learning approaches, such as reinforcement learning (RL), artificial neural networks (ANN), deep learning (DL), support vector machines (SVM), neuro-fuzzy systems, as well as evolutionary approaches (e.g., genetic algorithms and genetic programming). Such approaches enable the analysis of large, unstructured data in a dynamic, realtime, and algorithmic context, that requires minimal intervention by a portfolio manager, while making no assumptions about the statistical properties of the data or the behavior of financial markets. Table 2 provides an indicative list of recent studies with information about the methodologies used and the type of traded assets (stocks, equity indices, foreign exchange, portfolios).

Table 2. Studies using computational approaches for asset trading

\begin{tabular}{|c|c|c|}
\hline Study & Methodology & Asset \\
\hline Ang and Quek (2006) & Rule-based NFIS & Stocks \\
\hline Dempster and Leemans (2006) & $\mathrm{RL}$ & Forex \\
\hline Chavarnakul and Enke (2008) & ANN & Equity indices \\
\hline S.-T. Li and Kuo (2008) & SOM & Equity indices \\
\hline Dymova, Sevastianov, and Bartosiewicz (2010) & Fuzzy logic, DST & Stocks \\
\hline Gorgulho, Neves, and Horta (2011) & GA & Portfolios \\
\hline Kardas, Challenger, Yildirim, and Yamuc (2011) & Multi-agent system & Stocks \\
\hline Tan, Quek, and Cheng (2011) & RL, ANFIS & Stocks \\
\hline Creamer $(2012)$ & Boosting & Index futures \\
\hline Evans, Pappas, and Xhafa (2013) & ANN, GA & Forex \\
\hline Mabu, Hirasawa, Obayashi, and Kuremoto (2013) & GP & Stocks \\
\hline (Skabar, 2013) & Graph-based model & Stocks \\
\hline Booth, Gerding, and McGroarty (2014) & $\mathrm{RF}$ & Stocks \\
\hline Creamer (2015) & ANN, SA & Portfolios \\
\hline Hazan and Kale (2015) & Online algorithm & Portfolios \\
\hline Sermpinis, Stasinakis, Theofilatos, and Karathanasopoulos (2015) & SVM, GA & Forex \\
\hline J. Zhang and Maringer (2015) & RL, GA & Stocks \\
\hline Heaton, Polson, and Witte (2016) & $\mathrm{DL}$ & Equity indices \\
\hline Berutich, López, Luna, and Quintana (2016) & GP & Stocks \\
\hline Almahdi and Yang (2017) & $\mathrm{RL}$ & Portfolios, ETF \\
\hline Sermpinis, Stasinakis, Rosillo, and de la Fuente (2017) & SVM & ETF \\
\hline Abbaszadeh, Nguyen, and Wu (2018) & $\mathrm{DP}$ & Stocks \\
\hline Carapuço, Neves, and Horta (2018) & $\mathrm{RL}$ & Forex \\
\hline Feuerriegel and Gordon (2018) & $\mathrm{TM}, \mathrm{SA}$ & Equity indices \\
\hline Fiévet and Sornette (2018) & DT, Markov models & Stocks \\
\hline Nakano, Takahashi, and Takahashi (2018) & ANN & Cryptocurrencies \\
\hline Pendharkar and Cusatis (2018) & RL & Equity indices \\
\hline Yang, Lai, Wu, and Fang (2018) & Ridge regression & Portfolios \\
\hline Jeong and Kim (2019) & $\mathrm{DL}$ & Equity indices \\
\hline
\end{tabular}

ANFIS: adaptive neuro-fuzzy inference system, ANN: artificial neural network, DT: decision trees, ETF: exchange-traded funds, Forex: foreign exchange, GA: genetic algorithm, DL: deep learning, DP: dynamic programming, GP: genetic programming, DST: Dempster-Shafer theory, RL: reinforcement learning, SA: sentiment analysis, SOM: self-organizing map, SVM: support vector machines, TM: text mining

\subsection{Credit risk modeling}

Credit risk is one of the main areas of financial risk management that is of major interest not only for financial institutions providing credit, but also for non-financial corporations, as well as for individual consumers. Credit risk arises when borrowers fail to meet their debt obligations towards their creditors. Credit risk management has been at the core of all regulatory provisions enforced in the financial sector throughout the past two decades (i.e., the Basel Committee capital accords). Existing regulatory requirements constitute a quite stringent framework for modeling, measuring, and

\footnotetext{
${ }^{1}$ https://bit.1y/20yGUDu and https://bit.1y/20ulcXf (accessed: 8 November, 2018)
} 
managing credit risk, at least by credit institutions. Moreover, new reporting standards (i.e., International Financial Reporting Standards 9) have direct implications for credit risk management for non-financial companies.

The main components of credit risk modeling include the probability of loan default (PD), the losses given default (LGD), and the exposure at default (EAD), which define the expected losses of a loan or a loan portfolio:

$$
\text { Expected loss }=(P D)(L G D)(E A D)
$$

Credit models have become quite sophisticated over the years, covering various types of credit exposures, such as corporate loans, bond issues, consumer loans, and special purpose loans (e.g., project finance). The following subsections overview the use of computational and analytical techniques in credit scoring and rating and loss given default estimation. Further details on the procedures and techniques applied in this field can be found in the works of Baesens and Van Gestel (2009) and Doumpos, Lemonakis, Niklis, and Zopounidis (2019).

\subsubsection{Credit scoring and rating}

Credit scoring and rating models are fundamental components of credit risk analysis. Such models assess the creditworthiness of borrowers, provide PD estimates, and assign borrowers to risk rating classes, combining various types of information from the financial markets, about the characteristics of the loan and the borrower, as well as data about the external environment.

Credit scoring/rating models can be judgmental or quantitative. The former are used when historical data are lacking or for special types of credit assessments (e.g., project finance), whereas the latter are the ones preferred in most other cases (Doumpos et al., 2019). Quantitative models rely on the analysis of loan default data using analytical estimation models. Under the most common setting, data about defaulted and non-defaulted loans/borrowers are used for model fitting. Each data instance is described through various attributes (features) representing the risk level of the loan or the borrower. The output of a model fitted on such data is usually expressed in the form of a risk score, which can be associated with a PD estimate and a risk rating.

In this setting, statistical techniques such as logistic regression are widely used in practice. The main advantage of such approaches is that they are straightforward to apply and the resulting models are easy to comprehend, due to their linear form. Moreover, applying standard statistical techniques to big data poses no computational issues. However, despite the convenience of using linear credit risk scoring/rating models, their predictive performance may be inferior to more general models that allow the identification of more complex risk patterns that describe credit risk more accurately. While the performance gains can be marginal (if any) when limited information (attributes) is available, it can be become significant when rich information is considered. Over the years, credit risk data have become much more comprehensive, combining information from various traditional and alternative sources, such as from the financial markets, corporate data, personal data, historical deliquesces, as well as social networks, corporate networks, news, etc. (Galil \& Soffer, 2011; Gül, Kabak, \& Topcu, 2018; Óskarsdóttir, Bravo, Sarraute, Vanthienen, \& Baesens, 2018; Smales, 2016; Wei, Yildirim, den Bulte, \& Dellarocas, 2016). In this context, advanced modeling methodologies have a lot of potential to provide significantly improved results. 
Data analytics approaches based on machine learning and operations research techniques have been widely used in this area. Among others, three main methodological schemes can be identified:

- Single model approaches relying on the construction of credit risk models using a single methodology. The most commonly techniques are machine learning algorithms, such as neural networks, kernel methods, classification trees and decision rules, fuzzy and neuro-fuzzy systems, Bayesian models, etc. (Bellotti \& Crook, 2009b; Capotorti \& Barbanera, 2012; G. Chen \& Åstebro, 2012; Chrzanowska, Alfaro, \& Witkowska, 2009; Kvamme, Sellereite, Aas, \& Sjursen, 2018; Luo, Wu, \& Wu, 2017; Serrano-Cinca \& Gutiérrez-Nieto, 2016; Sreekantha \& Kulkarni, 2012). Other methodologies include multicriteria decision making/aiding (Angilella \& Mazzù, 2018; Doumpos \& Figueira, 2019; Doumpos \& Zopounidis, 2011; Ferreira, Esperança, Xavier, Costa, \& Pérez-Gladish, 2018; García, Giménez, \& Guijarro, 2013; Gavalas \& Syriopoulos, 2014; GutiérrezNieto, Serrano-Cinca, \& Camón-Cala, 2014), and optimization techniques (He, Zhang, Shi, \& Huang, 2010; Iazzolino, Bruni, \& Beraldi, 2013; A. Li, Shi, \& He, 2008; Peng, Kou, Shi, \& Chen, 2008).

- Ensembles combining multiple base models developed either through a single classifier or multiple algorithms to derived improved combined forecasts. The success of ensemble schemes depends on the diversity of the base models' results and reduction of their bias and/or variance. Popular ensemble approaches include various variants of bagging and boosting algorithms, which have been shown to provide very good results in several cases (Abellán \& Castellano, 2017; Bequé \& Lessmann, 2017; Finlay, 2011; Marqués, García, \& Sánchez, 2012).

- Hybrid systems, which rely on the combination of different techniques for feature/sample selection and model fitting as well as different modeling schemes (Doumpos, Niklis, Zopounidis, \& Andriosopoulos, 2015; Niklis, Doumpos, \& Zopounidis, 2014; Oreski, Oreski, \& Oreski, 2012; Yeh, Lin, \& Hsu, 2012; Yu, Wang, \& Lai, 2009; Z. Zhang, Gao, \& Shi, 2014).

A comprehensive comparative assessment of various learning algorithms and methodologies on various credit risk assessment data sets can be found in the work of Lessmann, Baesens, Seow, and Thomas (2015). Similar techniques are also used in other related fields such as profit and behavioral scoring (J. N. Crook, Edelman, \& Thomas, 2007; Thomas, 2009) and bankruptcy prediction (Alaka et al., 2018). It is worth noting and as analytical models for credit risk analysis become more complex, their comprehensibility becomes a major issue, particularly from a supervisory point of view. To address this issue, methodologies combining comprehensible systems (e.g., rule-based models) with advanced modeling algorithms have been proposed (Baesens, Setiono, Mues, \& Vanthienen, 2003; Florez-Lopez \& Ramon-Jeronimo, 2015; Martens, Baesens, Gestel, \& Vanthienen, 2007).

Concerning model construction, it is worth noting that often, given a large number of features and available information, the selection of the best risk predictors is a cumbersome process. Computational approaches facilitating feature selection have been widely used to address this difficulty, usually through metaheuristics (Marqués, García, \& Sánchez, 2013; Serrano-Silva, Villuendas-Rey, \& Yáñez-Márquez, 2018). Similar algorithms have also been used to optimize the parameters of fitting algorithms or to enable the consideration of complex performance measures (Finlay, 2009; Kozeny, 2015; J. Li, Wei, Li, \& Xu, 2011; Martens et al., 2010; T. Zhang, Dai, \& Ma, 2015; Zong-Chang, Hong, Ji-sheng, \& Hong, 2015), as well as for calibrating credit 
ratings (Lyra, Paha, Paterlini, \& Winker, 2010).

Finally, it is worth noting that while most of the above approaches mostly follow a static approach providing risk estimates for a fixed time period, another line of research has adopted models that incorporate dynamic characteristics. Typical examples include survival and hazard models that consider time-varying variables and enable the modeling of the time to default (Bellotti \& Crook, 2009a, 2014; J. Crook \& Bellotti, 2010; Dirick, Claeskens, \& Baesens, 2017; Serrano-Cinca, Gutiérrez-Nieto, \& López-Palacios, 2015), whereas credit migration (i.e., the dynamics of credit ratings) is commonly model with Markov models (Baena-Mirabete \& Puig, 2017; D'Amico, Janssen, \& Manca, 2016; Quirini \& Vannucci, 2014).

\subsubsection{Loss given default}

Loss given default (LGD) is the second major component of credit risk modeling. LGD refers to the losses that a creditor expects to face in the event of a loan default. The losses are expressed as percentage of the credit exposure (i.e., the outstanding amount) and refers to a chosen time period (e.g., one year).

Unlike models for PD estimation the prediction of LGD requires a regression modeling approach. According to (Scheule, Baesens, \& Roesch, 2016), LGD models can be classified in three main categories. The first category involves single-stage LGD models, which are based on a standard regression setting. Such models can be constructed with simple OLS estimation (with some transformation of LGD to take into account that is lies in $[0,1]$ ), as well as with other regression models, such as beta regression, quantile regression, and machine learning techniques. Single-stage models, however, do not take into consideration that LGD is conditional on loan default, which leads to a sample selection bias that is further evident by the fact that many defaulted loans do not lead to losses (Do, Rsch, \& Scheule, 2018). A second type of models addresses this limitation through multi-stage schemes that provide PD and LGD estimates. For instance, in a two-stage setting, a classification model is used to obtain PD estimates and a regression model is used for LGD prediction. More refined multi-stage settings are also possible with more elaborate structures, e.g., by separating fully cured defaulted loans from loans with losses (Do et al., 2018). A final class of LGD estimation models involves advanced approaches that consider non-observable random effects and complex dependencies between loan defaults and losses.

Comparative evaluations of various LGD estimation approaches can be found in the works of Loterman, Brown, Martens, Mues, and Baesens (2012) and Qi and Zhao (2011). Both studies concluded that non-parametric models outperform parametric ones for single-stage LGD estimation. Loterman et al. (2012) further examined twostage models and found that they are competitive to non-linear single-stage models, with the advantage of having a more comprehensible structure. Table 3 provides an indicative list of recent studies on the use of various methodologies for estimating LGD.

\subsubsection{Loan portfolio management}

Credit risk models for PD and LGD estimation are fundamental tools not only for the analysis of individual loans but also for managing loan portfolios. Loan portfolio management focuses on the estimation of losses at the portfolio level to derive a loss distribution that allows the specification of capital requirements for financial institutions. Typically, the loss distribution for loan portfolios is right-skewed. Losses that 
Table 3. Indicative list of recent studies on LGD modeling

\begin{tabular}{llll}
\hline Study & Methodology & Estimation approach & Type of loans \\
\hline Chava, Stefanescu, and Turnbull (2011) & Hazard model & Advanced & Corporate loans \& bonds \\
Bastos (2013) & Ensembles & Single-stage & Corporate bonds \\
Bonini and Caivano (2014) & Credibility theory & Advanced & Retail loans \\
Calabrese (2014) & Mixture model & Advanced & Personal loans \\
Leow, Mues, and Thomas (2014) & LR+OLS & Multi-stage & Mortgage \& personal loans \\
Tobback, Martens, Gestel, and Baesens (2014) & SVM & Multi-stage & Consumer \& corporate loans \\
Bijak and Thomas (2015) & Bayesian model & Multi-stage & Personal loans \\
X. Yao, Crook, and Andreeva (2015) & SVM & Multi-stage & Bonds \\
Krger and Rsch (2017) & QR & Single-stage & Corporate loans \\
Nazemi, Pour, Heidenreich, and Fabozzi (2017) & Ensembles, DE & Single-stage & Bonds \\
X. Yao, Crook, and Andreeva (2017) & SVM & Multi-stage & Credit cards \\
Cheng and Cirillo (2018) & SURV & Multi-stage & Consumer loans \\
Do et al. (2018) & Probit+OLS & Multi-stage & Mortgage loans \\
Krger, Oehme, Rsch, and Scheule (2018) & Copula model & Advanced & Bonds \\
J.-Y. Kim and Cho (2019) & DL & Single-stage & P2P lending \\
\hline
\end{tabular}

DE: differential evolution, DL: deep learning, LR: logistic regression, OLS: ordinary least squares, QR: quantile regression, SURV: survival analysis, SVM: support vector machines

do not exceed the expected loss, are covered by provisions, whereas higher losses up to an unexpected loss level, define the needed capital requirements (Witzany, 2017). The unexpected loss level is specified by value-at-risk measures at the $99.9 \%$ confidence level.

Loan portfolio management has some similarities to investment portfolio selection, but there are also noticeable differences, too. In both contexts, correlations play a fundamental role for risk modeling and diversification (Scheule et al., 2016). However, in loan portfolios market values and historical prices are unavailable for most types of loans (except for bonds). Well-known industry models, such as CreditMetrics, CreditRisk+, and KMV Portfolio Manager (Crouhy, Galai, \& Mark, 2000), rely on structural and reduced form approaches based on financial models originating from the work of Merton (1974) on the pricing of corporate debt and its generalization by Vasicek (1987) for portfolios of corporate loans.

While traditional financial approaches focus on modeling the loss distribution for loan portfolios, alternative computational methodologies have been proposed to extend the loan portfolio management setting, covering issues like:

- dynamic portfolio management with stochastic and dynamic programming models (Bo \& Capponi, 2017; Capponi \& Figueroa-López, 2012; Rasmussen \& Clausen, 2007; Valladão, Veiga, \& Street, 2018),

- optimization models for value-at-risk optimization (Iscoe, Kreinin, Mausser, \& Romanko, 2012; Mencía, 2012),

- computationally efficient simulation methods (Başoğlu, Hrmann, \& Sak, 2018; Glasserman, Kang, \& Shahabuddin, 2008; G. Liu, 2015; Sak \& Hrmann, 2012)

- Markov chain models for portfolios of consumer loans (Malik \& Thomas, 2010), and

- exact and evolutionary approaches for optimizing the composition of loan portfolios as well as for collateral management (Blank et al., 2017; Y. Guo, Zhou, Luo, Liu, \& Xiong, 2016; Ivorra, Mohammadi, \& Ramos, 2007; Metawa, Hassan, \& Elhoseny, 2017; Sirignano, Tsoukalas, \& Giesecke, 2016)

\subsection{Other areas of applications in banking, investments, and insurance}

Except for the areas covered in the previous sections regarding portfolio management and credit risk analysis, computational approaches and data analytics are also relevant 
in various other financial problems, including, among others, asset-liability and debt management, asset pricing, volatility modeling, operational and liquidity risk modeling, financial fraud detection, venture capital investments, efficiency analysis, mergers and acquisitions, and country risk modeling. Table 4 presents a list of recent research works on some of these subjects. It should be noted that this compiled list does not include works about the efficiency and performance of financial organizations, which is a very active area of research, but it has been covered in existing reviews, such as the work of Fethi and Pasiouras (2010). From the studies reported in Table 4 it is evident that areas involving financial planning decisions rely on computational optimization approaches, usually in a stochastic context, which allows the consideration and modeling of uncertainties. On the other hand, in other domains such as volatility modeling and fraud detection, the main focus is on developing predictive models for decision making. In such areas, data analytic approaches (e.g., machine learning) have been the most popular methodologies.

\section{Conclusions and future research}

Financial services is a very broad sector dealing with various types of problems with diverse features and characteristics. The sector's reliance on modeling tools has intensified over the years, and the level of analytical sophistication has also grown significantly. Thus, nowadays, financial services is not just an area where existing quantitative methodologies from other fields can be applied and tested in practice, but it also a field that promotes the development of new technological and analytical advances. The combination of characteristics such as the existence of massive real-time financial data, deep uncertainties, multiple actors and stakeholders, together with a tightening regulatory requirement, and the dynamic nature of the financial world, constantly create new modeling and computational challenges.

In this review we provided a synopsis of the applications, uses, and contributions of computational methodologies and data analytic techniques in this area. Popular topics like portfolio management and credit risk analysis were used as examples to illustrative the different techniques that have been recently used to address various types of financial decisions, in a prescriptive, descriptive and predictive setting. These techniques, include among others, different forms of exact optimization models (e.g., static, dynamic, robust, stochastic, etc.), metaheuristics, machine learning systems, and decision analysis.

Despite the progress that has been made in developing comprehensive, realistic, and accurate analytical tools for financial decision making, several research and practical challenges remain open. For instance, an important issue is the development of meaningful and effective integrated systems taking advantage of different analytical tools to allow the coverage of the multiple facets of financial problems in a unified context. Moreover, the comprehensibility and transparency of analytical models are crucial consideration for the adoption of new technologies and systems in practice, together with their incorporation into the existing procedures and protocols of financial institutions and organizations. While the trade-off between comprehensibility/transparency and performance is a challenge that does not have a global answer applicable to all settings, implementations in new types of decision support systems taking advantage of new technologies for visualization, reporting, and man-machine interaction, will certainly facilitate to the resolution of that trade-off. Moreover, techniques that allow the processing of various types of unstructured data (qualitative and quantitative) col- 
Table 4. Summary of studies about applications of analytical and computational models in various areas of financial decision making

\begin{tabular}{|c|c|}
\hline Study & Methodology \\
\hline \multicolumn{2}{|l|}{ Asset-liability management } \\
\hline $\begin{array}{l}\text { Kosmidou and Zopounidis (2008) } \\
\text { Asimit, Badescu, Siu, and Zinchenko (2013) } \\
\text { Glpinar and Pachamanova (2013) } \\
\text { Viswanathan, Ranganatham, and Balasubramanian (2014) } \\
\text { Chiu and Wong (2012) } \\
\text { Duarte, Valladão, and Veiga (2017) } \\
\text { L. Xu, Zhang, and Yao (2017) } \\
\text { Consigli, Moriggia, Vitali, and Mercuri (2018) } \\
\text { Moriggia, Kopa, and Vitali (2018) }\end{array}$ & $\begin{array}{l}\text { Goal programming } \\
\text { Chance constrained programming } \\
\text { Robust optimization } \\
\text { Goal programming } \\
\text { Stochastic programming } \\
\text { Stochastic programming } \\
\text { Dynamic programming } \\
\text { Stochastic programming } \\
\text { Multi-objective stochastic programming }\end{array}$ \\
\hline \multicolumn{2}{|l|}{ Sovereign and corporate debt management } \\
\hline $\begin{array}{l}\text { Balibek and Kksalan (2010) } \\
\text { Consiglio and Staino (2012) } \\
\text { Valladão, Veiga, and Veiga (2014) } \\
\text { Consiglio, Lotfi, and Zenios (2018) }\end{array}$ & $\begin{array}{l}\text { Multi-objective stochastic programming } \\
\text { Stochastic programming } \\
\text { Stochastic programming } \\
\text { Linear programming }\end{array}$ \\
\hline \multicolumn{2}{|l|}{ Venture capital and initial public offerings } \\
\hline $\begin{array}{l}\text { Ko, Lin, and Yang (2011) } \\
\text { Aouni, Colapinto, and Torre (2014) } \\
\text { Bastı, Kuzey, and Delen (2015) } \\
\text { Afful-Dadzie and Afful-Dadzie (2016) } \\
\text { Quintana, Chávez, Luque Baena, and Luna (2018) } \\
\text { Tian, Xu, and Fujita (2018) } \\
\text { Zhong, Liu, Zhong, and Xiong (2018) }\end{array}$ & $\begin{array}{l}\text { Game theory } \\
\text { Fuzzy goal programming } \\
\text { Support vector machines } \\
\text { Multicriteria analysis } \\
\text { ANFIS, genetic optimization } \\
\text { Fuzzy systems } \\
\text { Bayesian inference, Markov Chain Monte Carlo }\end{array}$ \\
\hline \multicolumn{2}{|l|}{ Operational and liquidity risk modeling } \\
\hline $\begin{array}{l}\text { Chavez-Demoulin, Embrechts, and Nešlehová (2006) } \\
\text { Shevchenko (2009) } \\
\text { Aquaro et al. (2010) } \\
\text { Shevchenko (2011) } \\
\text { Sanford and Moosa (2012) } \\
\text { Janabi, Hernandez, Berger, and Nguyen (2017) } \\
\text { Eling and Jung (2018) } \\
\text { Peña, Bonet, Lochmuller, Chiclana, and Góngora (2018) } \\
\text { Azar and Dolatabad (2019) }\end{array}$ & $\begin{array}{l}\text { Extreme value theory } \\
\text { Bayesian inference } \\
\text { Bayesian networks } \\
\text { Bayesian inference } \\
\text { Bayesian networks } \\
\text { Copula modeling } \\
\text { Copula modeling } \\
\text { Adaptive fuzzy inference model } \\
\text { Fuzzy cognitive maps }\end{array}$ \\
\hline \multicolumn{2}{|l|}{ Derivatives and volatility modeling } \\
\hline $\begin{array}{l}\text { Bandi and Bertsimas (2014) } \\
\text { Quek, Pasquier, and Kumar (2007) } \\
\text { X. Liu, Cao, Ma, and Shen (2019) } \\
\text { Y. Yao et al. (2017) } \\
\text { H. Y. Kim and Won (2018) } \\
\text { Bezerra and Albuquerque (2016) } \\
\text { Zeng and Klabjan (2018) }\end{array}$ & $\begin{array}{l}\text { Linear programming } \\
\text { Neural networks } \\
\text { Wavelets } \\
\text { Neural networks } \\
\text { Deep learning } \\
\text { Support vector machines } \\
\text { Support vector machines }\end{array}$ \\
\hline \multicolumn{2}{|l|}{ Financial fraud detection } \\
\hline $\begin{array}{l}\text { Gaganis (2009) } \\
\text { Dikmen and Küçükkocaoğlu (2010) } \\
\text { Glancy and Yadav (2011) } \\
\text { Abbasi, Albrecht, Vance, and Hansen (2012) } \\
\text { Sahin, Bulkan, and Duman (2013) } \\
\text { Balla, Gaganis, Pasiouras, and Zopounidis (2014) } \\
\text { S.-Y. Huang, Tsaih, and Yu (2014) } \\
\text { Throckmorton, Mayew, Venkatachalam, and Collins (2015) } \\
\text { Colladon and Remondi (2017) } \\
\text { Didimo, Giamminonni, Liotta, Montecchiani, and Pagliuca (2018) } \\
\text { D. Huang, Mu, Yang, and Cai (2018) } \\
\text { Nami and Shajari (2018) }\end{array}$ & $\begin{array}{l}\text { Multicriteria analysis, machine learning } \\
\text { Integer programming } \\
\text { Text mining } \\
\text { Stacked generalization } \\
\text { Decision trees } \\
\text { Multicriteria analysis } \\
\text { Self-organizing maps } \\
\text { Bayesian classifier } \\
\text { Network analysis } \\
\text { Network analysis } \\
\text { Graph-based models } \\
\text { Random forests, nearest neighbors }\end{array}$ \\
\hline
\end{tabular}

lected through non-traditional sources (e.g., online sources, news, etc.), could further improve the effectiveness of existing models and decision support tools. Finally, the integration of analytical models with finance theory would promote their use to a wider audience and further facilitate their adoption by practitioners in financial services. 


\section{References}

Abbasi, A., Albrecht, C., Vance, A., \& Hansen, J. (2012). MetaFraud: A meta-learning framework for detecting financial fraud. MIS Quarterly, 36(4), 1293-1327.

Abbaszadeh, S., Nguyen, T.-D., \& Wu, Y. (2018). Optimal trading under nonnegativity constraints using approximate dynamic programming. Journal of the Operational Research Society. (forthcoming)

Abellán, J., \& Castellano, J. G. (2017). A comparative study on base classifiers in ensemble methods for credit scoring. Expert Systems with Applications, 73, $1-10$.

Afful-Dadzie, E., \& Afful-Dadzie, A. (2016). A decision making model for selecting start-up businesses in a government venture capital scheme. Management Decision, 54 (3), 714-734.

Alaka, H. A., Oyedele, L. O., Owolabi, H. A., Kumar, V., Ajayi, S. O., Akinade, O. O., \& Bilal, M. (2018). Systematic review of bankruptcy prediction models: Towards a framework for tool selection. Expert Systems with Applications, 94, 164-184.

Allevi, E., Basso, A., Bonenti, F., Oggioni, G., \& Riccardi, R. (2018). Measuring the environmental performance of green SRI funds: A DEA approach. Energy Economics. (forthcoming)

Almahdi, S., \& Yang, S. Y. (2017). An adaptive portfolio trading system: A risk-return portfolio optimization using recurrent reinforcement learning with expected maximum drawdown. Expert Systems with Applications, 87, 267-279.

Andriosopoulos, K., Doumpos, M., Papapostolou, N. C., \& Pouliasis, P. K. (2013). Portfolio optimization and index tracking for the shipping stock and freight markets using evolutionary algorithms. Transportation Research Part E: Logistics and Transportation Review, 52, 16-34.

Andriosopoulos, K., \& Nomikos, N. (2014). Performance replication of the spot energy index with optimal equity portfolio selection: Evidence from the UK, US and Brazilian markets. European Journal of Operational Research, 234(2), $571-582$.

Ang, K., \& Quek, C. (2006). Stock trading using RSPOP: A novel rough set-based neuro-fuzzy approach. IEEE Transactions on Neural Networks, 17(5), 13011315.

Angelelli, E., Mansini, R., \& Speranza, M. G. (2008). A comparison of MAD and CVaR models with real features. Journal of Banking \& Finance, 32(7), 1188-1197.

Angilella, S., \& Mazzù, S. (2018). A credit risk model with an automatic override for innovative small and medium-sized enterprises, journal of the operational research society. Journal of the Operational Research Society. (forthcoming)

Aouni, B., Colapinto, C., \& Torre, D. L. (2014). A fuzzy goal programming model for venture capital investment decision making. INFOR: Information Systems and Operational Research, 52(3), 138-146.

Aouni, B., Doumpos, M., Pérez-Gladish, B., \& Steuer, R. E. (2018). On the increasing importance of multiple criteria decision aid methods for portfolio selection. Journal of the Operational Research Society. (forthcoming)

Aquaro, V., Bardoscia, M., Bellotti, R., Consiglio, A., Carlo, F. D., \& Ferri, G. (2010). A bayesian networks approach to operational risk. Physica A: Statistical Mechanics and its Applications, 389(8), 1721-1728.

Asimit, A. V., Badescu, A. M., Siu, T. K., \& Zinchenko, Y. (2013). Capital requirements and optimal investment with solvency probability constraints. IMA Journal of Management Mathematics, 26(4), 345-375. 
Azar, A., \& Dolatabad, K. M. (2019). A method for modelling operational risk with fuzzy cognitive maps and bayesian belief networks. Expert Systems with Applications, 115, 607-617.

Babalos, V., Philippas, N., Doumpos, M., \& Zopounidis, C. (2012). Mutual funds performance appraisal using stochastic multicriteria acceptability analysis. Applied Mathematics and Computation, 218(9), 5693-5703.

Babat, O., Vera, J. C., \& Zuluaga, L. F. (2018). Computing near-optimal valueat-risk portfolios using integer programming techniques. European Journal of Operational Research, 266 (1), 304-315.

Baena-Mirabete, S., \& Puig, P. (2017). Parsimonious higher order markov models for rating transitions. Journal of the Royal Statistical Society: Series A (Statistics in Society), $181(1), 107-131$.

Baesens, B., Setiono, R., Mues, C., \& Vanthienen, J. (2003). Using neural network rule extraction and decision tables for credit-risk evaluation. Management Science, $49(3), 312-329$.

Baesens, B., \& Van Gestel, T. (2009). Credit risk management: Basic concepts: Financial risk components, rating analysis, models, economic and regulatory capital. Oxford: Oxford University Press.

Balibek, E., \& Kksalan, M. (2010). A multi-objective multi-period stochastic programming model for public debt management. European Journal of Operational Research, 205(1), 205-217.

Balla, V., Gaganis, C., Pasiouras, F., \& Zopounidis, C. (2014). Multicriteria decision aid models for the prediction of securities class actions: evidence from the banking sector. OR Spectrum, 36(1), 57-72.

Ballestero, E., Bravo, M., Pérez-Gladish, B., Arenas-Parra, M., \& Plà-Santamaria, D. (2012). Socially responsible investment: A multicriteria approach to portfolio selection combining ethical and financial objectives. European Journal of Operational Research, 216(2), 487-494.

Ban, G.-Y., Karoui, N. E., \& Lim, A. E. B. (2018). Machine learning and portfolio optimization. Management Science, 64(3), 1136-1154.

Bandi, C., \& Bertsimas, D. (2014). Robust option pricing. European Journal of Operational Research, 239(3), 842-853.

Başoğlu, İ., Hrmann, W., \& Sak, H. (2018). Efficient simulations for a bernoulli mixture model of portfolio credit risk. Annals of Operations Research, 260(1-2), $113-128$.

Bastı, E., Kuzey, C., \& Delen, D. (2015, may). Analyzing initial public offerings: Shortterm performance using decision trees and SVMs. Decision Support Systems, 73, $15-27$.

Bastos, J. A. (2013). Ensemble predictions of recovery rates. Journal of Financial Services Research, 46(2), 177-193.

Bellotti, T., \& Crook, J. (2009a). Credit scoring with macroeconomic variables using survival analysis. Journal of the Operational Research Society, 60(12), 16991707.

Bellotti, T., \& Crook, J. (2009b). Support vector machines for credit scoring and discovery of significant features. Expert Systems with Applications, 36(2), 33023308 .

Bellotti, T., \& Crook, J. (2014). Retail credit stress testing using a discrete hazard model with macroeconomic factors. Journal of the Operational Research Society, $65(3), 340-350$.

Bequé, A., \& Lessmann, S. (2017). Extreme learning machines for credit scoring: An 
empirical evaluation. Expert Systems with Applications, 86, 42-53.

Bertsimas, D., \& Shioda, R. (2007). Algorithm for cardinality-constrained quadratic optimization. Computational Optimization and Applications, 43(1), 1-22.

Bertsimas, D., \& Sim, M. (2004). The price of robustness. Operations Research, 52(1), $35-53$.

Berutich, J. M., López, F., Luna, F., \& Quintana, D. (2016). Robust technical trading strategies using GP for algorithmic portfolio selection. Expert Systems with Applications, 46, 307-315.

Bezerra, P. C. S., \& Albuquerque, P. H. M. (2016). Volatility forecasting via SVR-GARCH with mixture of Gaussian kernels. Computational Management Science, 14 (2), 179-196.

Bijak, K., \& Thomas, L. C. (2015). Modelling LGD for unsecured retail loans using bayesian methods. Journal of the Operational Research Society, 66(2), 342352.

Bjrk, T., Murgoci, A., \& Zhou, X. Y. (2012). Mean-variance portfolio optimization with state-dependent risk aversion. Mathematical Finance, 24 (1), 1-24.

Blank, B., Lunceford, E., Morik, J., He, S., Rana, M., Rajendran, P., .. Kompella, P. L. (2017). BNY mellon optimization reduces intraday credit risk by $\$ 1.4$ trillion. Interfaces, ${ }_{4} 7(1), 38-51$.

Bloembergen, D., Tuyls, K., Hennes, D., \& Kaisers, M. (2015). Evolutionary dynamics of multi-agent learning: A survey. Journal of Artificial Intelligence Research, 53, 659-697.

Bo, L., \& Capponi, A. (2014, sep). Optimal investment in credit derivatives portfolio under contagion risk. Mathematical Finance, 26(4), 785-834.

Bo, L., \& Capponi, A. (2017). Robust optimization of credit portfolios. Mathematics of Operations Research, 42(1), 30-56.

Boginski, V., Butenko, S., \& Pardalos, P. M. (2005). Statistical analysis of financial networks. Computational Statistics \& Data Analysis, 48(2), 431-443.

Bonini, S., \& Caivano, G. (2014). Estimating loss-given default through advanced credibility theory. The European Journal of Finance, 22(13), 1351-1362.

Booth, A., Gerding, E., \& McGroarty, F. (2014). Automated trading with performance weighted random forests and seasonality. Expert Systems with Applications, 41(8), 3651-3661.

Bordino, I., Battiston, S., Caldarelli, G., Cristelli, M., Ukkonen, A., \& Weber, I. (2012). Web search queries can predict stock market volumes. PLoS ONE, $7(7), \mathrm{e} 40014$.

Brown, D. B., \& Smith, J. E. (2011). Dynamic portfolio optimization with transaction costs: Heuristics and dual bounds. Management Science, 57(10), 1752-1770.

Calabrese, R. (2014). Downturn loss given default: Mixture distribution estimation. European Journal of Operational Research, 237(1), 271-277.

Calafiore, G. C. (2008). Multi-period portfolio optimization with linear control policies. Automatica, 44(10), 2463-2473.

Capotorti, A., \& Barbanera, E. (2012). Credit scoring analysis using a fuzzy probabilistic rough set model. Computational Statistics \& Data Analysis, 56(4), 981-994.

Capponi, A., \& Figueroa-López, J. E. (2012). Dynamic portfolio optimization with a defaultable security and regime-switching. Mathematical Finance, 24(2), 207249.

Carapuço, J., Neves, R., \& Horta, N. (2018). Reinforcement learning applied to forex trading. Applied Soft Computing, 73, 783-794. 
Çelikyurt, U., \& Özekici, S. (2007). Multiperiod portfolio optimization models in stochastic markets using the mean-variance approach. European Journal of Operational Research, 179(1), 186-202.

Chang, T.-J., Meade, N., Beasley, J., \& Sharaiha, Y. (2000). Heuristics for cardinality constrained portfolio optimisation. Computers $\& 3$ Operations Research, 27(13), 1271-1302.

Charnes, A., Cooper, W. W., \& Ijiri, Y. (1963). Breakeven budgeting and programming to goals. Journal of Accounting Research, 1(1), 16-43.

Chava, S., Stefanescu, C., \& Turnbull, S. (2011). Modeling the loss distribution. Management Science, 57(7), 1267-1287.

Chavarnakul, T., \& Enke, D. (2008, feb). Intelligent technical analysis based equivolume charting for stock trading using neural networks. Expert Systems with Applications, 34 (2), 1004-1017.

Chavez-Demoulin, V., Embrechts, P., \& Nešlehová, J. (2006). Quantitative models for operational risk: Extremes, dependence and aggregation. Journal of Banking $\mathcal{E}_{3}$ Finance, 30(10), 2635-2658.

Chen, C., \& sha Zhou, Y. (2018). Robust multiobjective portfolio with higher moments. Expert Systems with Applications, 100, 165-181.

Chen, G., \& Åstebro, T. (2012). Bound and collapse bayesian reject inference for credit scoring. Journal of the Operational Research Society, 63(10), 1374-1387.

Chen, H.-H. (2008). Stock selection using data envelopment analysis. Industrial Management \& Data Systems, 108(9), 1255-1268.

Cheng, D., \& Cirillo, P. (2018). A reinforced urn process modeling of recovery rates and recovery times. Journal of Banking \& Finance, 96, 1-17.

Chiu, M. C., \& Wong, H. Y. (2012). Mean-variance asset-liability management: Cointegrated assets and insurance liability. European Journal of Operational Research, 223(3), 785-793.

Christodoulakis, G. A., \& Satchell, S. (2008). The analytics of risk model validation. London: Academic Press.

Chrzanowska, M., Alfaro, E., \& Witkowska, D. (2009). The individual borrowers recognition: Single and ensemble trees. Expert Systems with Applications, 36(3), 6409-6414.

Colapinto, C., La Torre, D., \& Aouni, B. (2018). Goal programming for financial portfolio management: a state-of-the-art review. Operational Research. (forthcoming)

Colladon, A. F., \& Remondi, E. (2017). Using social network analysis to prevent money laundering. Expert Systems with Applications, 67, 49-58.

Consigli, G., Moriggia, V., Vitali, S., \& Mercuri, L. (2018). Optimal insurance portfolios risk-adjusted performance through dynamic stochastic programming. Computational Management Science, 15(3-4), 599-632.

Consiglio, A., Lotfi, S., \& Zenios, S. A. (2018). Portfolio diversification in the sovereign credit swap markets. Annals of Operations Research, 266(1-2), 5-33.

Consiglio, A., \& Staino, A. (2012). A stochastic programming model for the optimal issuance of government bonds. Annals of Operations Research, 193(1), 159172.

Creamer, G. (2012). Model calibration and automated trading agent for euro futures. Quantitative Finance, 12(4), 531-545.

Creamer, G. (2015). Can a corporate network and news sentiment improve portfolio optimization using the Black-Litterman model? Quantitative Finance, 15(8), 1405-1416. 
Crook, J., \& Bellotti, T. (2010). Time varying and dynamic models for default risk in consumer loans. Journal of the Royal Statistical Society: Series A (Statistics in Society), $173(2), 283-305$.

Crook, J. N., Edelman, D. B., \& Thomas, L. C. (2007). Recent developments in consumer credit risk assessment. European Journal of Operational Research, $183(3), 1447-1465$.

Crouhy, M., Galai, D., \& Mark, R. (2000). A comparative analysis of current credit risk models. Journal of Banking \&6 Finance, 24(1-2), 59-117.

D’Amico, G., Janssen, J., \& Manca, R. (2016). Downward migration credit risk problem: a non-homogeneous backward semi-markov reliability approach. Journal of the Operational Research Society, 67(3), 393-401.

Dempster, M., \& Leemans, V. (2006). An automated FX trading system using adaptive reinforcement learning. Expert Systems with Applications, 30(3), 543-552.

de Paulo, W. L., de Oliveira, E. M., \& do Valle Costa, O. L. (2016). Enhanced index tracking optimal portfolio selection. Finance Research Letters, 16, 93-102.

Didimo, W., Giamminonni, L., Liotta, G., Montecchiani, F., \& Pagliuca, D. (2018). A visual analytics system to support tax evasion discovery. Decision Support Systems, 110, 71-83.

Dikmen, B., \& Küçükkocaoğlu, G. (2010). The detection of earnings manipulation: the three-phase cutting plane algorithm using mathematical programming. Journal of Forecasting, 29, 442-466.

Dirick, L., Claeskens, G., \& Baesens, B. (2017). Time to default in credit scoring using survival analysis: a benchmark study. Journal of the Operational Research Society, 68(6), 652-665.

Do, H. X., Rsch, D., \& Scheule, H. (2018). Predicting loss severities for residential mortgage loans: A three-step selection approach. European Journal of Operational Research, 270(1), 246-259.

do Castelo Gouveia, M., Neves, E. D., Dias, L. C., \& Antunes, C. H. (2018). Performance evaluation of portuguese mutual fund portfolios using the value-based DEA method. Journal of the Operational Research Society. (forthcoming)

Doumpos, M., \& Figueira, J. R. (2019). A multicriteria outranking approach for modeling corporate credit ratings: An application of the ELECTRE TRI-nC method. Omega, 82, 166-180.

Doumpos, M., Lemonakis, C., Niklis, D., \& Zopounidis, C. (2019). Analytical techniques in the assessment of credit risk. New York: Springer.

Doumpos, M., Niklis, D., Zopounidis, C., \& Andriosopoulos, K. (2015). Combining accounting data and a structural model for predicting credit ratings: Empirical evidence from european listed firms. Journal of Banking \& Finance, 50, 599607.

Doumpos, M., \& Zopounidis, C. (2011). A multicriteria outranking modeling approach for credit rating. Decision Sciences, 42(3), 721-742.

Doumpos, M., \& Zopounidis, C. (2014). Multicriteria analysis in finance. New York: Springer.

Duarte, T. B., Valladão, D. M., \& Veiga, Á. (2017). Asset liability management for open pension schemes using multistage stochastic programming under solvencyII-based regulatory constraints. Insurance: Mathematics and Economics, 77, 177-188.

Dupačová, J., \& Kopa, M. (2012). Robustness in stochastic programs with risk constraints. Annals of Operations Research, 200(1), 55-74.

Dymova, L., Sevastianov, P., \& Bartosiewicz, P. (2010). A new approach to the 
rule-base evidential reasoning: Stock trading expert system application. Expert Systems with Applications, 37(8), 5564-5576.

Edirisinghe, N., \& Zhang, X. (2007). Generalized DEA model of fundamental analysis and its application to portfolio optimization. Journal of Banking \& Finance, 31(11), 3311-3335.

Edirisinghe, N., \& Zhang, X. (2008). Portfolio selection under DEA-based relative financial strength indicators: case of US industries. Journal of the Operational Research Society, 59(6), 842-856.

Eling, M., \& Jung, K. (2018). Copula approaches for modeling cross-sectional dependence of data breach losses. Insurance: Mathematics and Economics, 82, $167-180$.

Ertenlice, O., \& Kalayci, C. B. (2018). A survey of swarm intelligence for portfolio optimization: Algorithms and applications. Swarm and Evolutionary Computation, 39, 36-52.

Evans, C., Pappas, K., \& Xhafa, F. (2013). Utilizing artificial neural networks and genetic algorithms to build an algo-trading model for intra-day foreign exchange speculation. Mathematical and Computer Modelling, 58(5-6), 1249-1266.

Fabozzi, F. J., Kolm, P. N., Pachamanova, D. A., \& Focardi, S. M. (2007). Robust portfolio optimization and management. New York: John Wiley.

Ferreira, F., Esperança, J., Xavier, M., Costa, R., \& Pérez-Gladish, B. (2018). A socio-technical approach to the evaluation of social credit applications. Journal of the Operational Research Society. (forthcoming)

Fethi, M. D., \& Pasiouras, F. (2010). Assessing bank efficiency and performance with operational research and artificial intelligence techniques: A survey. European Journal of Operational Research, 204 (2), 189-198.

Feuerriegel, S., \& Gordon, J. (2018, aug). Long-term stock index forecasting based on text mining of regulatory disclosures. Decision Support Systems, 112, 88-97.

Fiévet, L., \& Sornette, D. (2018). Decision trees unearth return sign predictability in the S\&P 500. Quantitative Finance. (forthcoming)

Filippi, C., Guastaroba, G., \& Speranza, M. (2016). A heuristic framework for the bi-objective enhanced index tracking problem. Omega, 65, 122-137.

Filomena, T. P., \& Lejeune, M. A. (2012). Stochastic portfolio optimization with proportional transaction costs: Convex reformulations and computational experiments. Operations Research Letters, 40(3), 212-217.

Finlay, S. (2009). Are we modelling the right thing? the impact of incorrect problem specification in credit scoring. Expert Systems with Applications, 36(5), 90659071.

Finlay, S. (2011). Multiple classifier architectures and their application to credit risk assessment. European Journal of Operational Research, 210(2), 368-378.

Florez-Lopez, R., \& Ramon-Jeronimo, J. M. (2015). Enhancing accuracy and interpretability of ensemble strategies in credit risk assessment: A correlated-adjusted decision forest proposal. Expert Systems with Applications, 42(13), 5737-5753.

Gaganis, C. (2009). Classification techniques for the identification of falsified financial statements: a comparative analysis. Intelligent Systems in Accounting, Finance \& Management, 16(3), 207-229.

Gaivoronski, A., \& Pflug, G. (2005). Value-at-risk in portfolio optimization: properties and computational approach. The Journal of Risk, 7(2), 1-31.

Galagedera, D. U., Roshdi, I., Fukuyama, H., \& Zhu, J. (2018). A new network DEA model for mutual fund performance appraisal: An application to U.S. equity mutual funds. Omega, 77, 168-179. 
Galil, K., \& Soffer, G. (2011). Good news, bad news and rating announcements: An empirical investigation. Journal of Banking \& Finance, 35(11), 3101-3119.

García, F., Giménez, V., \& Guijarro, F. (2013). Credit risk management: A multicriteria approach to assess creditworthiness. Mathematical and Computer Modelling, 57(7-8), 2009-2015.

Gavalas, D., \& Syriopoulos, T. (2014). An integrated credit rating and loan quality model: application to bank shipping finance. Maritime Policy 83 Management, 42(6), 533-554.

Geva, T., \& Zahavi, J. (2014). Empirical evaluation of an automated intraday stock recommendation system incorporating both market data and textual news. Decision Support Systems, 57, 212-223.

Giesecke, K., Kim, B., Kim, J., \& Tsoukalas, G. (2014). Optimal credit swap portfolios. Management Science, 60(9), 2291-2307.

Glancy, F. H., \& Yadav, S. B. (2011). A computational model for financial reporting fraud detection. Decision Support Systems, 50(3), 595-601.

Glasserman, P., Kang, W., \& Shahabuddin, P. (2008). Fast simulation of multifactor portfolio credit risk. Operations Research, 56(5), 1200-1217.

Glen, J. J. (2011). Mean-variance portfolio rebalancing with transaction costs and funding changes. Journal of the Operational Research Society, 62(4), 667-676.

Glpinar, N., \& Pachamanova, D. (2013). A robust optimization approach to assetliability management under time-varying investment opportunities. Journal of Banking \& Finance, 37(6), 2031-2041.

Goldfarb, D., \& Iyengar, G. (2003). Robust portfolio selection problems. Mathematics of Operations Research, 28(1), 1-38.

Goldstein, M. A., Kumar, P., \& Graves, F. C. (2014). Computerized and highfrequency trading. Financial Review, 49(2), 177-202.

Gorgulho, A., Neves, R., \& Horta, N. (2011). Applying a GA kernel on optimizing technical analysis rules for stock picking and portfolio composition. Expert Systems with Applications, 38(11), 14072-14085.

Gül, S., Kabak, Ö., \& Topcu, I. (2018). A multiple criteria credit rating approach utilizing social media data. Data $\&$ Knowledge Engineering, 116, 80-99.

Guo, X., Zhang, H., \& Tian, T. (2018). Development of stock correlation networks using mutual information and financial big data. PLoS ONE, 13(4), e0195941.

Guo, Y., Zhou, W., Luo, C., Liu, C., \& Xiong, H. (2016). Instance-based credit risk assessment for investment decisions in P2P lending. European Journal of Operational Research, $249(2), 417-426$.

Gupta, P., Mehlawat, M. K., \& Saxena, A. (2008). Asset portfolio optimization using fuzzy mathematical programming. Information Sciences, 178(6), 1734-1755.

Gutiérrez-Nieto, B., Serrano-Cinca, C., \& Camón-Cala, J. (2014). A credit score system for socially responsible lending. Journal of Business Ethics, 133(4), 691-701.

Hallerbach, W., Ning, H., Soppe, A., \& Spronk, J. (2004). A framework for managing a portfolio of socially responsible investments. European Journal of Operational Research, 153(2), 517-529.

Hamzaçebi, C., \& Pekkaya, M. (2011). Determining of stock investments with grey relational analysis. Expert Systems with Applications, 38(8), 9186-9195.

Hazan, E., \& Kale, S. (2015). An online portfolio selection algorithm with regret logarithmic in price variation. Mathematical Finance, 25(2), 288-310.

He, J., Zhang, Y., Shi, Y., \& Huang, G. (2010). Domain-driven classification based on multiple criteria and multiple constraint-level programming for intelligent 
credit scoring. IEEE Transactions on Knowledge and Data Engineering, 22(6), 826-838.

Heaton, J. B., Polson, N. G., \& Witte, J. H. (2016). Deep learning for finance: deep portfolios. Applied Stochastic Models in Business and Industry, 33(1), 3-12.

Hibiki, N. (2006). Multi-period stochastic optimization models for dynamic asset allocation. Journal of Banking \& Finance, 30(2), 365-390.

Hillier, F. S. (1963). The derivation of probabilistic information for the evaluation of risky investments. Management Science, 9(3), 443-457.

Huang, C.-F. (2012). A hybrid stock selection model using genetic algorithms and support vector regression. Applied Soft Computing, 12(2), 807-818.

Huang, D., Mu, D., Yang, L., \& Cai, X. (2018). CoDetect: Financial fraud detection with anomaly feature detection. IEEE Access, 6, 19161-19174.

Huang, S.-Y., Tsaih, R.-H., \& Yu, F. (2014). Topological pattern discovery and feature extraction for fraudulent financial reporting. Expert Systems with Applications, 41(9), 4360-4372.

Iazzolino, G., Bruni, M. E., \& Beraldi, P. (2013). Using DEA and financial ratings for credit risk evaluation: an empirical analysis. Applied Economics Letters, 20(14), 1310-1317.

Iscoe, I., Kreinin, A., Mausser, H., \& Romanko, O. (2012). Portfolio credit-risk optimization. Journal of Banking \&5 Finance, 36(6), 1604-1615.

Ivorra, B., Mohammadi, B., \& Ramos, A. M. (2007). Optimization strategies in credit portfolio management. Journal of Global Optimization, 43(2-3), 415-427.

Janabi, M. A. A., Hernandez, J. A., Berger, T., \& Nguyen, D. K. (2017). Multivariate dependence and portfolio optimization algorithms under illiquid market scenarios. European Journal of Operational Research, 259(3), 1121-1131.

Jeong, G., \& Kim, H. Y. (2019). Improving financial trading decisions using deep q-learning: Predicting the number of shares, action strategies, and transfer learning. Expert Systems with Applications, 117, 125-138.

Jobst, N., Horniman, M., Lucas, C., \& Mitra, G. (2001). Computational aspects of alternative portfolio selection models in the presence of discrete asset choice constraints. Quantitative Finance, 1(5), 489-501.

Jondeau, W., \& Rockinger, M. (2006). Optimal portfolio allocation under higher moments. European Financial Management, 12(1), 29-55.

Jorion, P. (2009). Value at risk (3rd ed.). New York: McGraw-Hill.

Jung, J., \& Kim, S. (2015). An adaptively managed dynamic portfolio selection model using a time-varying investment target according to the market forecast. Journal of the Operational Research Society, 66(7), 1115-1131.

Kalyagin, V. A., Koldanov, A. P., Koldanov, P. A., \& Pardalos, P. M. (2017). Optimal decision for the market graph identification problem in a sign similarity network. Annals of Operations Research, 266(1-2), 313-327.

Kapsos, M., Christofides, N., \& Rustem, B. (2014). Worst-case robust omega ratio. European Journal of Operational Research, 234(2), 499-507.

Kardas, G., Challenger, M., Yildirim, S., \& Yamuc, A. (2011). Design and implementation of a multiagent stock trading system. Software: Practice and Experience, 42(10), 1247-1273.

Kim, H. Y., \& Won, C. H. (2018). Forecasting the volatility of stock price index: A hybrid model integrating LSTM with multiple GARCH-type models. Expert Systems with Applications, 103, 25-37.

Kim, J.-Y., \& Cho, S.-B. (2019). Deep dense convolutional networks for repayment prediction in peer-to-peer lending. In M. Graña et al. (Eds.), International 
joint conference SOCO'18-CISIS'18-ICEUTE'18 (pp. 134-144). Cham: Springer International Publishing.

Kim, W. C., Kim, J. H., Ahn, S. H., \& Fabozzi, F. J. (2012). What do robust equity portfolio models really do? Annals of Operations Research, 205(1), 141-168.

Kiris, S., \& Ustun, O. (2012). An integrated approach for stock evaluation and portfolio optimization. Optimization, 61(4), 423-441.

Ko, C.-C., Lin, T. T., \& Yang, C. (2011). The venture capital entry model on game options with jump-diffusion process. International Journal of Production Economics, 134(1), 87-94.

Kosmidou, K., \& Zopounidis, C. (2008). Generating interest rate scenarios for bank asset liability management. Optimization Letters, 2(2), 157-169.

Kozeny, V. (2015). Genetic algorithms for credit scoring: Alternative fitness function performance comparison. Expert Systems with Applications, 42 (6), 2998-3004.

Krger, S., Oehme, T., Rsch, D., \& Scheule, H. (2018). A copula sample selection model for predicting multi-year LGDs and lifetime expected losses. Journal of Empirical Finance, 47, 246-262.

Krger, S., \& Rsch, D. (2017). Downturn LGD modeling using quantile regression. Journal of Banking \& Finance, 79, 42-56.

Kvamme, H., Sellereite, N., Aas, K., \& Sjursen, S. (2018). Predicting mortgage default using convolutional neural networks. Expert Systems with Applications, 102, 207-217.

Leow, M., Mues, C., \& Thomas, L. (2014). The economy and loss given default: evidence from two UK retail lending data sets. Journal of the Operational Research Society, 65(3), 363-375.

Lessmann, S., Baesens, B., Seow, H.-V., \& Thomas, L. C. (2015). Benchmarking state-of-the-art classification algorithms for credit scoring: An update of research. European Journal of Operational Research, 247(1), 124-136.

Li, A., Shi, Y., \& He, J. (2008). MCLP-based methods for improving "bad" catching rate in credit cardholder behavior analysis. Applied Soft Computing, 8(3), 12591265.

Li, J., Wei, L., Li, G., \& Xu, W. (2011). An evolution strategy-based multiple kernels multi-criteria programming approach: The case of credit decision making. Decision Support Systems, 51(2), 292-298.

Li, S.-T., \& Kuo, S. (2008). Knowledge discovery in financial investment for forecasting and trading strategy through wavelet-based SOM networks. Expert Systems with Applications, 34(2), 935-951.

Liu, G. (2015). Simulating risk contributions of credit portfolios. Operations Research, $63(1), 104-121$.

Liu, H., Mulvey, J., \& Zhao, T. (2016). A semiparametric graphical modelling approach for large-scale equity selection. Quantitative Finance, 16(7), 1053-1067.

Liu, Q., Guo, Z., \& Wang, J. (2012, feb). A one-layer recurrent neural network for constrained pseudoconvex optimization and its application for dynamic portfolio optimization. Neural Networks, 26, 99-109.

Liu, X., Cao, Y., Ma, C., \& Shen, L. (2019). Wavelet-based option pricing: An empirical study. European Journal of Operational Research, 272(3), 1132-1142.

Lobo, M. S., Fazel, M., \& Boyd, S. (2006). Portfolio optimization with linear and fixed transaction costs. Annals of Operations Research, 152(1), 341-365.

Loterman, G., Brown, I., Martens, D., Mues, C., \& Baesens, B. (2012). Benchmarking regression algorithms for loss given default modeling. International Journal of Forecasting, 28(1), 161-170. 
Lotfi, S., \& Zenios, S. A. (2018). Robust VaR and CVaR optimization under joint ambiguity in distributions, means, and covariances. European Journal of Operational Research, 269(2), 556-576.

Luo, C., Wu, D., \& Wu, D. (2017). A deep learning approach for credit scoring using credit default swaps. Engineering Applications of Artificial Intelligence, 65, 465-470.

Lyra, M., Paha, J., Paterlini, S., \& Winker, P. (2010). Optimization heuristics for determining internal rating grading scales. Computational Statistics $\&$ Data Analysis, 54 (11), 2693-2706.

Mabu, S., Hirasawa, K., Obayashi, M., \& Kuremoto, T. (2013). Enhanced decision making mechanism of rule-based genetic network programming for creating stock trading signals. Expert Systems with Applications, 40(16), 6311-6320.

Malik, M., \& Thomas, L. C. (2010). Modelling credit risk of portfolio of consumer loans. Journal of the Operational Research Society, 61(3), 411-420.

Maringer, D. (2005). Portfolio management with heuristic optimization. Dordrecht: Springer-Verlag.

Maringer, D., \& Parpas, P. (2007). Global optimization of higher order moments in portfolio selection. Journal of Global Optimization, 43(2-3), 219-230.

Markowitz, H. M. (1959). Portfolio selection: Efficient diversification of investment. New York: John Wiley \& Sons.

Marqués, A., García, V., \& Sánchez, J. (2012). Two-level classifier ensembles for credit risk assessment. Expert Systems with Applications, 39(12), 10916-10922.

Marqués, A., García, V., \& Sánchez, S. (2013). A literature review on the application of evolutionary computing to credit scoring. Journal of the Operational Research Society, 64(9), 1384-1399.

Martens, D., Baesens, B., Gestel, T. V., \& Vanthienen, J. (2007). Comprehensible credit scoring models using rule extraction from support vector machines. European Journal of Operational Research, 183(3), 1466-1476.

Martens, D., Gestel, T. V., Backer, M. D., Haesen, R., Vanthienen, J., \& Baesens, B. (2010). Credit rating prediction using ant colony optimization. Journal of the Operational Research Society, 61(4), 561-573.

Mencía, J. (2012). Assessing the risk-return trade-off in loan portfolios. Journal of Banking 8 Finance, 36(6), 1665-1677.

Merton, R. C. (1974). On the pricing of corporate debt: The risk structure of interest rates. The Journal of Finance, 29(2), 449.

Metawa, N., Hassan, M. K., \& Elhoseny, M. (2017). Genetic algorithm based model for optimizing bank lending decisions. Expert Systems with Applications, 80, $75-82$.

Mezali, H., \& Beasley, J. E. (2013). Quantile regression for index tracking and enhanced indexation. Journal of the Operational Research Society, 64(11), 16761692.

Mitra, G., \& Mitra, L. (Eds.). (2011). The handbook of news analytics in finance. New York: John Wiley \& Sons, Ltd.

Moriggia, V., Kopa, M., \& Vitali, S. (2018). Pension fund management with hedging derivatives, stochastic dominance and nodal contamination. Omega.

Myers, S., \& Pogue, G. (1974). A programming approach to corporate financial management. The Journal of Finance, 29(2), 579-599.

Nakano, M., Takahashi, A., \& Takahashi, S. (2018). Bitcoin technical trading with artificial neural network. Physica A: Statistical Mechanics and its Applications, $510,587-609$. 
Nami, S., \& Shajari, M. (2018). Cost-sensitive payment card fraud detection based on dynamic random forest and $k$-nearest neighbors. Expert Systems with Applications, 110, 381-392.

Nazemi, A., Pour, F. F., Heidenreich, K., \& Fabozzi, F. J. (2017). Fuzzy decision fusion approach for loss-given-default modeling. European Journal of Operational Research, 262(2), 780-791.

Ngai, E., Hu, Y., Wong, Y., Chen, Y., \& Sun, X. (2011). The application of data mining techniques in financial fraud detection: A classification framework and an academic review of literature. Decision Support Systems, 50(3), 559-569.

Niklis, D., Doumpos, M., \& Zopounidis, C. (2014). Combining market and accountingbased models for credit scoring using a classification scheme based on support vector machines. Applied Mathematics and Computation, 234, 69-81.

Oreski, S., Oreski, D., \& Oreski, G. (2012, nov). Hybrid system with genetic algorithm and artificial neural networks and its application to retail credit risk assessment. Expert Systems with Applications, 39(16), 12605-12617.

Óskarsdóttir, M., Bravo, C., Sarraute, C., Vanthienen, J., \& Baesens, B. (2018). The value of big data for credit scoring: Enhancing financial inclusion using mobile phone data and social network analytics. Applied Soft Computing. (forthcoming)

Östermark, R. (2017). Massively parallel processing of recursive multi-period portfolio models. European Journal of Operational Research, 259(1), 344-366.

Pätäri, E., Karell, V., Luukka, P., \& Yeomans, J. S. (2018). Comparison of the multicriteria decision-making methods for equity portfolio selection: The U.S. evidence. European Journal of Operational Research, 265(2), 655-672.

Peña, A., Bonet, I., Lochmuller, C., Chiclana, F., \& Góngora, M. (2018). Flexible inverse adaptive fuzzy inference model to identify the evolution of operational value at risk for improving operational risk management. Applied Soft Computing, 65, 614-631.

Pendharkar, P. C., \& Cusatis, P. (2018). Trading financial indices with reinforcement learning agents. Expert Systems with Applications, 103, 1-13.

Peng, Y., Kou, G., Shi, Y., \& Chen, Z. (2008). A multi-criteria convex quadratic programming model for credit data analysis. Decision Support Systems, 44(4), $1016-1030$.

Pfister, T., Utz, S., \& Wimmer, M. (2014). Capital allocation in credit portfolios in a multi-period setting: a literature review and practical guidelines. Review of Managerial Science, 9(1), 1-32.

Post, T., \& Kopa, M. (2017). Portfolio choice based on third-degree stochastic dominance. Management Science, 63(10), 3381-3392.

Qi, M., \& Zhao, X. (2011). Comparison of modeling methods for loss given default. Journal of Banking $\&$ Finance, 35 (11), 2842-2855.

Quah, T. (2008). DJIA stock selection assisted by neural network. Expert Systems with Applications, 35(1-2), 50-58.

Quek, C., Pasquier, M., \& Kumar, N. (2007). A novel recurrent neural network-based prediction system for option trading and hedging. Applied Intelligence, 29(2), $138-151$.

Quintana, D., Chávez, F., Luque Baena, R. M., \& Luna, F. (2018). Fuzzy techniques for IPO underpricing prediction. Journal of Intelligent and Fuzzy Systems, 35(1), $367-381$.

Quirini, L., \& Vannucci, L. (2014). Creditworthiness dynamics and hidden markov models. Journal of the Operational Research Society, 65(3), 323-330. 
Rasmussen, K. M., \& Clausen, J. (2007). Mortgage loan portfolio optimization using multi-stage stochastic programming. Journal of Economic Dynamics and Control, 31(3), 742-766.

Rockafellar, R., \& Uryasev, S. (2002, jul). Conditional value-at-risk for general loss distributions. Journal of Banking \& Finance, 26(7), 1443-1471.

Ryoo, H. S. (2007). A compact mean-variance-skewness model for large-scale portfolio optimization and its application to the NYSE market. Journal of the Operational Research Society, 58(4), 505-515.

Sahin, Y., Bulkan, S., \& Duman, E. (2013). A cost-sensitive decision tree approach for fraud detection. Expert Systems with Applications, 40(15), 5916-5923.

Sak, H., \& Hrmann, W. (2012). Fast simulations in credit risk. Quantitative Finance, 12(10), 1557-1569.

Sanford, A. D., \& Moosa, I. A. (2012). A bayesian network structure for operational risk modelling in structured finance operations. Journal of the Operational Research Society, 63(4), 431-444.

Scheule, H., Baesens, B., \& Roesch, D. (2016). Credit risk analytics: Measurement techniques, applications, and examples in SAS. John Wiley \& Sons Inc.

Schumaker, R. P., Zhang, Y., Huang, C.-N., \& Chen, H. (2012). Evaluating sentiment in financial news articles. Decision Support Systems, 53(3), 458-464.

Sermpinis, G., Stasinakis, C., Rosillo, R., \& de la Fuente, D. (2017). European exchange trading funds trading with locally weighted support vector regression. European Journal of Operational Research, 258(1), 372-384.

Sermpinis, G., Stasinakis, C., Theofilatos, K., \& Karathanasopoulos, A. (2015). Modeling, forecasting and trading the EUR exchange rates with hybrid rolling genetic algorithms - support vector regression forecast combinations. European Journal of Operational Research, 247(3), 831-846.

Serrano-Cinca, C., \& Gutiérrez-Nieto, B. (2016). The use of profit scoring as an alternative to credit scoring systems in peer-to-peer (P2P) lending. Decision Support Systems, 89, 113-122.

Serrano-Cinca, C., Gutiérrez-Nieto, B., \& López-Palacios, L. (2015). Determinants of default in P2P lending. PLoS ONE, 10(10), e0139427.

Serrano-Silva, Y. O., Villuendas-Rey, Y., \& Yáñez-Márquez, C. (2018). Automatic feature weighting for improving financial decision support systems. Decision Support Systems, 107, 78-87.

Sevastjanov, P., \& Dymova, L. (2009). Stock screening with use of multiple criteria decision making and optimization. Omega, 37(3), 659-671.

Shevchenko, P. V. (2009). Implementing loss distribution approach for operational risk. Applied Stochastic Models in Business and Industry, 26(3), 277-307.

Shevchenko, P. V. (2011). Modelling operational risk using bayesian inference. Berlin Heidelberg: Springer.

Sirignano, J. A., Tsoukalas, G., \& Giesecke, K. (2016). Large-scale loan portfolio selection. Operations Research, 64 (6), 1239-1255.

Skabar, A. (2013). Direction-of-change financial time series forecasting using a similarity-based classification model. Journal of Forecasting, 32(5), 409-422.

Smales, L. (2016). News sentiment and bank credit risk. Journal of Empirical Finance, $38,37-61$.

Song, Q., Liu, A., \& Yang, S. Y. (2017). Stock portfolio selection using learning-to-rank algorithms with news sentiment. Neurocomputing, 264, 20-28.

Sreekantha, D. K., \& Kulkarni, R. V. (2012). Expert system design for credit risk evaluation using neuro-fuzzy logic. Expert Systems, 29(1), 56-69. 
Strub, O., \& Baumann, P. (2018). Optimal construction and rebalancing of indextracking portfolios. European Journal of Operational Research, 264(1), 370387.

Tan, Z., Quek, C., \& Cheng, P. Y. (2011). Stock trading with cycles: A financial application of ANFIS and reinforcement learning. Expert Systems with Applications, $38(5), 4741-4755$.

Thomas, L. C. (2009). Consumer credit models. Oxford, UK: Oxford University Press.

Throckmorton, C. S., Mayew, W. J., Venkatachalam, M., \& Collins, L. M. (2015, jun). Financial fraud detection using vocal, linguistic and financial cues. Decision Support Systems, 74, 78-87.

Tian, X., Xu, Z., \& Fujita, H. (2018). Sequential funding the venture project or not? a prospect consensus process with probabilistic hesitant fuzzy preference information. Knowledge-Based Systems, 161, 172-184.

Tobback, E., Martens, D., Gestel, T. V., \& Baesens, B. (2014). Forecasting loss given default models: impact of account characteristics and the macroeconomic state. Journal of the Operational Research Society, 65(3), 376-392.

Treleaven, P., Galas, M., \& Lalchand, V. (2013). Algorithmic trading review. Communications of the ACM, 56(11), 76-85.

Valladão, D. M., Veiga, Á., \& Street, A. (2018). A linear stochastic programming model for optimal leveraged portfolio selection. Computational Economics, 51(4), 1021-1032.

Valladão, D. M., Veiga, Á., \& Veiga, G. (2014). A multistage linear stochastic programming model for optimal corporate debt management. European Journal of Operational Research, 237(1), 303-311.

van der Hart, J., Slagter, E., \& van Dijk, D. (2003). Stock selection strategies in emerging markets. Journal of Empirical Finance, 10(1-2), 105-132.

Vasicek, O. A. (1987). Probability of loss on loan portfolio. (KMV Corporation, USA)

Vercher, E., \& Bermudez, J. D. (2013). A possibilistic mean-downside risk-skewness model for efficient portfolio selection. IEEE Transactions on Fuzzy Systems, $21(3), 585-595$.

Viswanathan, P., Ranganatham, M., \& Balasubramanian, G. (2014). Modeling asset allocation and liability composition for indian banks. Managerial Finance, 40(7), 700-723.

Wei, Y., Yildirim, P., den Bulte, C. V., \& Dellarocas, C. (2016). Credit scoring with social network data. Marketing Science, 35(2), 234-258.

Witzany, J. (2017). Credit risk management - pricing, measurement, and modeling. Cham, Switzerland: Springer.

Woodside-Oriakhi, M., Lucas, C., \& Beasley, J. (2011). Heuristic algorithms for the cardinality constrained efficient frontier. European Journal of Operational Research, 213(3), 538-550.

Xidonas, P., Mavrotas, G., Hassapis, C., \& Zopounidis, C. (2017). Robust multiobjective portfolio optimization: A minimax regret approach. European Journal of Operational Research, 262(1), 299-305.

Xidonas, P., Mavrotas, G., Krintas, T., Psarras, J., \& Zopounidis, C. (2012). Multicriteria portfolio management. New York: Springer.

Xidonas, P., Mavrotas, G., \& Psarras, J. (2010). A multiple criteria decision-making approach for the selection of stocks. Journal of the Operational Research Society, $61(8), 1273-1287$.

Xidonas, P., Mavrotas, G., Zopounidis, C., \& Psarras, J. (2011). IPSSIS: An in- 
tegrated multicriteria decision support system for equity portfolio construction and selection. European Journal of Operational Research, 210(2), 398-409.

Xu, L., Zhang, L., \& Yao, D. (2017). Optimal investment and reinsurance for an insurer under markov-modulated financial market. Insurance: Mathematics and Economics, 74, 7-19.

Xu, X., He, F., Chen, R., \& Zhang, Q. (2015). Solving non-linear portfolio optimization problems with interval analysis. Journal of the Operational Research Society, 66 (6), 885-893.

Yan, W., \& Clack, C. D. (2010). Evolving robust GP solutions for hedge fund stock selection in emerging markets. Soft Computing, 15(1), 37-50.

Yang, P.-Y., Lai, Z.-R., Wu, X., \& Fang, L. (2018). Trend representation based logdensity regularization system for portfolio optimization. Pattern Recognition, $76,14-24$.

Yao, X., Crook, J., \& Andreeva, G. (2015). Support vector regression for loss given default modelling. European Journal of Operational Research, 240(2), 528-538.

Yao, X., Crook, J., \& Andreeva, G. (2017). Enhancing two-stage modelling methodology for loss given default with support vector machines. European Journal of Operational Research, 263(2), 679-689.

Yao, Y., Zhai, J., Cao, Y., Ding, X., Liu, J., \& Luo, Y. (2017). Data analytics enhanced component volatility model. Expert Systems with Applications, 84, 232-241.

Yeh, C.-C., Lin, F., \& Hsu, C.-Y. (2012). A hybrid KMV model, random forests and rough set theory approach for credit rating. Knowledge-Based Systems, 33, $166-172$.

Yu, L., Wang, S., \& Lai, K. K. (2009). An intelligent-agent-based fuzzy group decision making model for financial multicriteria decision support: The case of credit scoring. European Journal of Operational Research, 195(3), 942-959.

Zeng, Y., \& Klabjan, D. (2018). Online adaptive machine learning based algorithm for implied volatility surface modeling. Knowledge-Based Systems. (forthcoming)

Zenios, S., Consiglio, A., \& Nielsen, S. S. (2010). Practical financial optimization. New York: John Wiley \& Sons, Ltd.

Zhang, J., \& Maringer, D. (2015). Using a genetic algorithm to improve recurrent reinforcement learning for equity trading. Computational Economics, 47(4), $551-567$.

Zhang, T., Dai, Q., \& Ma, Z. (2015). Extreme learning machines' ensemble selection with GRASP. Applied Intelligence, 43(2), 439-459.

Zhang, Z., Gao, G., \& Shi, Y. (2014). Credit risk evaluation using multi-criteria optimization classifier with kernel, fuzzification and penalty factors. European Journal of Operational Research, 237(1), 335-348.

Zhao, Z., Xu, F., Wang, M., \& yi Zhang, C. (2018). A sparse enhanced indexation model with norm and its alternating quadratic penalty method. Journal of the Operational Research Society. (forthcoming)

Zhong, H., Liu, C., Zhong, J., \& Xiong, H. (2018). Which startup to invest in: a personalized portfolio strategy. Annals of Operations Research, 263(1-2), 339360.

Zong-Chang, Y., Hong, K., Ji-sheng, X., \& Hong, S. (2015). Artificial immune algorithm-based credit evaluation for mobile telephone customers. Journal of the Operational Research Society, 66 (9), 1533-1541.

Zopounidis, C., Doumpos, M., \& Niklis, D. (2018). Financial decision support: an overview of developments and recent trends. EURO Journal on Decision Processes, 6(1-2), 63-76. 